\title{
Are urban living labs the new normal in co-creating places?
}

Jonas Bylund, JPI Urban Europe / IQS, Stockholm, Sweden. jonas@jpi-urbaneurope.eu Johannes Riegler, [0000-000 I-5209-9864], JPI Urban Europe / FFG, Vienna, Austria. johannes.riegler@jpi-urbaneurope.eu Caroline Wrangsten, JPI Urban Europe / IQS Stockholm, Sweden. caroline.wrangsten@jpi-urbaneurope.eu

\section{JPI URBAN EUROPE IN A NUTSHELL}

JPI Urban Europe exists to tackle the grand societal challenge of sustainable urbanisation. It involves the collaboration of more than 20 European countries, with their ministries and funding agencies, drawing on national programming to coordinate and shape joint transnational activities. So far, more than 80 projects have been funded by seven joint calls whereof four have been in cooperation with Horizon 2020, with one more in the pipeline, and a few strictly in collaboration between member states. Currently developing collaborations with the Belmont Forum' and with China (NSFC), we continue to answer to the spirit of urgency expressed in international policies such as the UN Agenda 2030. As Wolfram et al (2019: 437) points to, many, if not most, of the challenges in the UN Agenda 2030 have to be tackled in urban settings in one way or another. We do this by adopting particularly Sustainable Development Goal (SDG) II as a gateway to other SDGs, and by shaping common frameworks, building critical mass in urban research and innovation, and mobilising a broad range of actors. The aim is to support local urban action for experimenting with and testing ways to tackle challenges, e.g. in resource use, mobility, housing, urban liveability, energy, etc. - activities whose ongoing effects result in feedback loops that include international sharing and dialogue on transition pathways. Ultimately, it compiles evidence on how to proceed with urban transformations that align with global goals and targets.

To support local action and urban policy, JPI Urban Europe has adopted a challenge-driven approach to research and innovation in order to avoid the risks of ill-suited solutions developed by research and innovation actors and to take into account challenges as they are articulated by the problem owners. Since 2019, this approach has somewhat merged with a dilemma-driven approach where the 'wickedness' and

\footnotetext{
' http://www.belmontforum.org
}

(C) The Author(s), 2020

Smaniotto Costa, C. et al. (Eds.): C3Places, Culture \& Territory 04, pp. 17-2I, 2020

https://doi.org//0.24I40/2020-sct-vol.4-0 
unexpectedness of urban issues is recognised across the complex settings within which urban sustainable development has to be implemented. An urban dilemma is defined as two or more competing goals, such as from stakeholder interests and related strategies, which potentially fail to achieve their aims when implementing one strategy hampers or prevents the achievement of another. In this sense, dilemmas articulate the challenges and wicked problems involved in liveable urban development. The dilemma-driven approach ultimately helps set up a platform where stakeholders can turn distrust and barriers into constructive and trusting, if not emphatic, transition pathways.

\section{WHY ARE URBAN LIVING LABS SO IMPORTANT FOR JPI URBAN EUROPE?}

Regarding urban transformations and transition pathways, where inclusive public spaces represent one key concern, urban experimentation is the key practise in urban dilemma situations to co-design pragmatic ways forward. JPI Urban Europe has supported more than 50 urban living labs in European urban settings. These labs have worked with dilemma situations ranging from urban governance, water management and e-participation to mobility management, inter-ethnic co-existence and stakeholder involvement. But there are a couple of more conceptual reasons why we consider urban living labs a kind of flagship among funded urban research and innovation practices.

Firstly, urban living labs is an approach, or set of methods (an umbrella), geared to make change happen in a co-creative way. It is a tool or instrument to change mindsets, processes and material solutions. Urban living labs can change the way we think of and actually practice urban governance. They are experimental approaches to address societal challenges by facilitating co-creation in everyday urban settings. They are spaces to experiment with new policies, co-design and test new methods to tackle specific urban challenges and to explore new governance models outside the conventional research and innovation laboratories (JPI Urban Europe, 20 19: 37). Urban living labs represent a means of collectively working on urban futures that support change and re-doing taken-for-granted practices in an inclusive manner. They are suitable to test and shape new knowledge around new solutions, as well as for translating existing solutions and processes from one urban setting to another. Proper urban living labs are more than simply projects or a collection of cases and examples. Societal sustainability challenges require new, transformed ways of organizing urban life, not just from individual citizens but also, and perhaps more so, from and in our contemporary governance structures and innovation contexts. In view of this backdrop, our position is that urban living labs can be useful and even necessary in urban transitioning, and we identify at least two specific reasons for why urban living labs are important to JPI Urban Europe:

- There is increased fragmentation in urban imaginaries and sectoral lines. Current silo and sectoral approaches risk becoming counter-productive as they 
risk generating wicked problems across and in urban settings. Urban living labs provide the means to highlight and tackle these kinds of challenges.

- While linear research and innovation models to tackle societal challenges are inadequate, urban living labs are well suited to work in non-linear urban innovation ecosystems with multi-stakeholder participation and diverse knowledge practices.

\section{CURRENT CHALLENGES}

Over the past decade, JPI Urban Europe has, thanks to worthwhile exchange with projects, reflexive research, practitioners and urbanists, uncovered areas for improvement for urban living lab projects and regimes. However, impactful projects have been under way in their specific context and few, if any, urban living labs have made concrete contributions to urban transformation. With regards to the wicked problems that urban areas, and society at large, is currently faced with, urban living labs cannot afford to do 'business as usual.' They must contribute with valuable and long-term actions to urban transformation processes. JPI Urban Europe has thus reached a set of conclusions regarding current challenges in the urban living lab approach:

\section{Equity and inclusiveness}

Who benefits from the lab, and who is in the room? Although co-creation and challenges are at the core of urban living labs - a lens of equity and inclusiveness with regards to these areas has been missing.

\section{Integration in local and regional 'proper' governance}

Current urban living labs sometimes run in parallel with institutions and governance, instead of in an integrated way. This affects the project's possibility to ensure longer term impact, and to be a resource in governance issues rather than a side runner.

\section{Capacity building in public administrations}

Urban living labs need to contribute to public administrations' capacity to work with wicked problems. Learning loops need to guide project developments. To a certain extent, our experiences correspond with those highlighted by Marvin et al. (20l8):

- Design: Longer term assessment and comparative analysis of how they are formed,

- Stabilisation and operation: increase conceptual and reflexive understanding,

- Impact: reshape our understanding of urban transitions and urban living labs' local particularities.

These issues have to be considered along the lines of shaping substantial learning and avoiding 'simple texting'. For instance, in urban design and public space matters, drawing on ongoing explorations and findings in the UN-Habitat coordinated Horizon 2020 project Urban Maestro, there is an identified need to better 
understand and build capacities for 'design governance' in Europe (and beyond), and particularly 'design exploration' or 'research by design' for how to manage and develop urban public spaces and a sense of place.

\section{LOOKING AHEAD}

Can urban living labs become 'the new normal' in co-creating places? We believe so. What it would take is, for instance, to re-organise the systems and business models (commercial as well as academic) that are built around the 'three-year project' timelines. Urban living labs' purposes and benefits would also need to be strategically and clearly communicated and understood in contexts where they are still far from being considered the new normal - keeping in mind, however, that urban living labs are not the answer to everything - the approach is not a silver bullet.

Urban public spaces fulfil important societal functions and shape many of the characteristics of cities and urban areas. Still, there are a number of dilemmas involved in their development and maintenance. Regarding urban public spaces, for instance, typical crossings of concerns are related to everyone's right to the city, climate change actions and how to cater for safety and security without promoting increasingly exclusive spaces (JPI Urban Europe, 2019: 27). Additionally, all these functions, dynamics and characteristics as well as how public spaces are formally and informally organized in general in urban areas determine if a given city is open or closed (Sennett, 2019). Placemakers seem to value the approach, according to a workshop held at the Placemaking Week Europe, Valencia 2019.

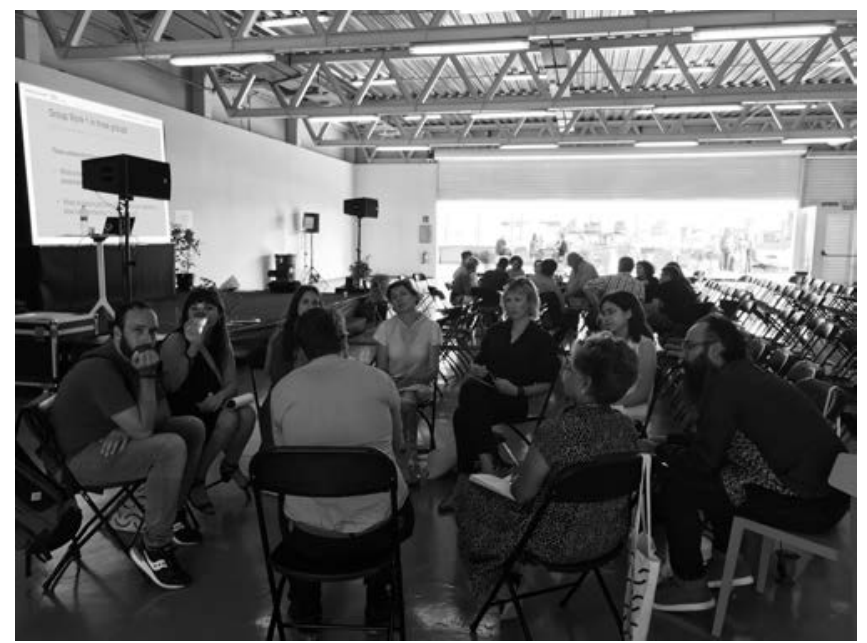

Fig. I: JPI Urban Europe workshop on urban living labs at Placemaking Week Europe, Valencia 2019. Photo: Bylund, 2019.

These urban living labs deal with multifaceted urban issues and are tools to maintain science-policy-society co-creation. Due to their territorial anchoring, they are highly 
context specific. As van Steenbergen \& Frantzeskaki (2018) show, urban living labs can be instruments to (unintentionally) contribute to placemaking by connecting (social) innovation to urban development. Hence, links between places (as well as non-human living entities) and people are generated, maintained and/or re-shaped, which may foster a sense of place and in turn urban sustainability transformation through these changing spaces (ibid.).

So, what would the development of urban living labs as 'the new normal' mean for the co-creation of urban places, neighbourhoods, and public open spaces? At times when 'innovation' is interpreted as technological quick fixes to the sustainability challenges at hand, something to be put on the market and trickle down to where it is most needed - there is seemingly much to be gained from considering the types of innovations evident when one goes 'back to the future', re-discovering the ways of doing urban life that humanity and planners seem to have forgotten about: trial and error, community-level designs, governance in proximity with the owners of (and experts in) urban public space - the local inhabitants.

The way we see it, 'Urban Living Labs 2.0' has the possibility to legitimise (placemaking and public space investments) and decentralize (power and decision making). If urban living labs could truly streamline with urban governance, realize and communicate their full learning potentials and many co-benefits to their environs, then the co-creation of open public spaces would no longer be considered a 'side activity' in urban strategies or a 'tick in the box' for citizen participation in decision making. It would be a self-explanatory and absolutely necessary instrument in sustainable urban development - an instrument which we, at this point in history, simply cannot afford to overlook.

\section{REFERENCES}

JPI Urban Europe (2019). Strategic Research and Innovation Agenda 2.0. Retrieved from https://jpiurbaneurope.eu/app/uploads/2019/02/SRIA2.0.pdf

Marvin, S., Bulkeley, H., Mai, L., McCormick, K., \& Voytenko Palgan, Y. (Eds.)(20I8). Urban living labs: Experimenting with city futures. New York: Routledge.

Sennett, R. (2019). The Fight for the City. Eurozine. Retrieved from https://www.eurozine.com/ the-fight-for-the-city/

Van Steenbergen, F. \& Frantzeskaki, N. (20I8). The embeddedness of ULL. In: Marvin, S., Bulkeley, H., Mai, L., McCormick, K., \& Voytenko Palgan, Y. (Eds.). Urban living labs: Experimenting with city futures. New York: Routledge.

Wolfram, M., Borgström, S. \& Farrely, M. (2019). Urban transformative capacity: From concept to practice. In Ambio 48(5): 437-448. Retrieved from https://link.springer.com/content/pdf/I0.1007\%2Fs |3280-019-0| 169-y.pdf

Wrangsten, C. \& Bylund, J. (2019). A dilemma-driven approach to urban innovation. Retrieved from https://jpi-urbaneurope.eu/news/a-dilemma-driven-approach-to-urban-innovation 